THÉMATA. Revista de Filosofía

$\mathrm{N}^{\mathrm{o}} 51$, Enero-junio (2015) pp.: 53-69

ISSN: 0212-8365 e-ISSN: 2253-900X

doi: 10.12795/themata.2015.i51.03

\title{
PRIMO LEVI, UN HUMANISTA CRÍTICO
}

\author{
PRIMO LEVI, A CRITIC HUMANIST
}

\author{
Ana Lucía Batalla Gavaldà ${ }^{1}$ \\ Universitat de València (España)
}

Recibido: 31-07-2014

Aceptado: 09-12-2014

\begin{abstract}
Resumen: La intención de este escrito es reflexionar sobre el pensamiento del italiano Primo Levi y defender como apropiado el referirnos a él como un 'humanista crítico'. Para ello seguimos los criterios propuestos por T. Todorov para caracterizar la doctrina humanista en tres elementos: autonomía del yo, finalidad del tú y universalidad de los ellos, y los propios del humanismo crítico, único posible tras lo ocurrido en Auschwitz y Kolyma: el reconocimiento del horror del que somos capaces los seres humanos y la afirmación de la posibilidad del bien.
\end{abstract}

Palabras-clave: Humanismo crítico, Campos de concentración, Sobreviviente,Testimonio, Memoria.

\begin{abstract}
The aim of this research is to reflect upon the thoughts of the Italian Primo Levi and the defense of referring to himself as a 'critic humanist'. Therefore, I based on the criteria proposed by T. Todorov to describe the humanism doctrine: the autonomy of the I, the finality of the you and the universality of the they; and the criteria for the critic humanism, the only regarded as possible after what happened in Auschwitz and Kolyma: acknowledgement of the horror that humans are capable to make, and the affirmation of the possibility of good. Key-words: Critic humanism, Concentration camps, Surviving, Testimony, Memory.
\end{abstract}

El objetivo de este texto será tratar aquellos elementos de la obra y la biografía del italiano Primo Levi que me llevan a calificarlo de 'humanista crítico'. Con este término sigo la concepción propuesta por Tzvetan Todorov en su obra titulada Memoria del mal, tentación del bien. En esta propone una varia-

[1] (ana.l.batalla@gmail.com) Licenciada en Filosofía por la Universidad de Valencia, interesada especialmente por la antropología filosófica, la historia conceptual y la hermenéutica filosófica. 
ción del concepto de humanismo que anteriormente había defendido en su obra El jardín imperfecto, que se caracterizaba por tres elementos esenciales: 1) El ser humano se encuentra en el origen de sus propios actos y es libre de llevarlos o no a cabo, esto es, actúa a partir de su propia voluntad; 2) El ser humano es el fin último de sus actos, que no apuntan a entidades supra o infrahumanas; 3) Dibuja el espacio en el que todos los seres humanos evolucionan, que únicamente les pertenece a ellos. Las fórmulas que utiliza para referirse a estas tres características son: autonomía del yo, finalidad del tú y universalidad de los ellos, respectivamente ${ }^{2}$.

En el año 2002, Todorov propondrá tomar como punto de partida los campos de concentración de Auschwitz y Kolyma para explicitar qué se puede entender por pensamiento humanista a partir de estos. El primero de los elementos que caracterizarían este humanismo crítico, que se enfrenta a una realidad muy diferente tras 'el corto siglo XX', será el reconocimiento del horror del que son capaces los seres humanos, tanto de causarlo como de sufrirlo; y el segundo elemento será una afirmación de la posibilidad del bien, «de un bien que conduce a tomar al hombre, en su identidad concreta e individual, como fin último de su acción, a quererlo y a amarlo» ${ }^{3}$. De este modo, el desafío al que se enfrentan los humanistas tras Auschwitz y Kolyma será el tratar de conciliar la innegable ausencia de ilusiones sobre el hombre con el mantenimiento del hombre como objetivo de su acción.

Lo que voy a hacer en este escrito será ver cómo afronta Primo Levi, sobreviviente de Auschwitz, este desafío humanista. Para ello, comentaré primero cómo cumple las características del pensamiento humanista en general, para pasar a continuación a ver si cumple las características más concretas del humanismo crítico, posterior a Auschwitz; a pesar de que, como no puede ser de otra manera, ambas caracterizaciones están profundamente interrelacionadas.

\section{La autonomía del yo}

El primer elemento que trataré para ver su reivindicación de la autonomía del yo es de dónde nació su vocación literaria, esto es: ¿por qué siente la necesidad de escribir sobre su experiencia en los campos de concentración alemanes? La pregunta así formulada permite intuir una respuesta: Levi es habitado por un sentimiento de liberación y alivio cuando escribe, es para él un 'acto terapéutico'4. Tal como el propio autor dice en el Prefacio del primero de sus libros: Si esto es un hombre, la necesidad de escribir nació en el Lager mismo:

[2] Todorov, T.: El jardin imperfecto. Luces y sombras del pensamiento humanista, Barcelona: Ed. Paidós, 2011; p. 46.

[3] Todorov, T.: Memoria del mal, tentación del bien. Indagación sobre el siglo XX, Barcelona: Ed. Península, 2002; p. 365.

[4] Traverso, E.: La historia desgarrada, Barcelona: Ed. Herder, 2001; p. 25.

THÉMATA. Revista de Filosofía, No 51 enero-junio (2015) pp.: 53-69

doi: 10.12795/themata.2015.i51.03 
«La necesidad de hablar a 'los demás', de hacer que 'los demás' supiesen, había asumido entre nosotros, antes de nuestra liberación y después de ella, el carácter de un impulso inmediato y violento, hasta el punto de que rivalizaba con nuestras demás necesidades más elementales; en primer lugar, por lo tanto, como una liberación interior» ${ }^{5}$.

Esta necesidad suya se reconoce común entre gran parte de los Häftlinge de los campos de concentración, ya que todos comparten un mismo sueño que les atormenta durante la noche: sueñan que han vuelto a sus casas, están reunidos con su familia, contándoles lo que les ocurrió durante este tiempo y nadie los escucha, sino que ignoran su relato e incluso salen de la sala en la que se encuentran sin dirigirles la palabra. Este sueño angustioso, que todavía les atormenta cuando son liberados del campo, testifica el miedo que sentían a que los alemanes ganasen la batalla y que, en el caso de que sobrevivieran, algo prácticamente impensable durante el tiempo que estuvieron en el Lager, nadie les iba a creer. Miedo a que los alemanes escribieran la historia y consiguieran que el mundo no creyese lo que ellos decían; a que se salieran con la suya, ya que como escribiría muchos años después en Los hundidos y los salvados, toda la historia del 'Reich milenario' puede releerse como una guerra contra la memoria, y esto será lo que él tratará de evitar mediante su escritura: evitar el olvido de lo que el ser humano ha sido capaz de hacer a sus semejantes.

Mientras ellos estaban dentro del Lager, e incluso antes de que ellos mismos entraran, ya se contaban relatos sobre lo que ocurría en estos campos de concentración. Pero los 'civiles' se resistían a creerlos, eran relatos demasiado despiadados para ser ciertos. Parecía que tenían razón en su sueño cuando pensaban que nadie les prestaría atención, preferirían ignorarles. Y él mismo hace algo parecido dentro del campo cuando unos compañeros le cuentan que los elegidos en las selecciones tenían como destino las cámaras de gas. Él, por miedo a creer en lo que le dicen, insinúa que tal vez se los llevan a otros campos y por eso no los vuelven a ver; por lo que su compañero deja de insistir entristeciéndose: 'No quiere entenderlo'. Esta es, creo yo, una actitud comprensible, podría decir 'humana': el querer apartar la mirada cuando algo nos resulta molesto. A esta actitud se refiere en su novela titulada Sistema periódico describiéndola como su modo de reaccionar cuando se enteró todavía en Italia de lo que ocurría en los Lager alemanes: «Si se quería sacar algún provecho de la juventud que aún bullía en nuestras venas, no nos quedaba verdaderamente otro recurso que la ceguera voluntaria» (Système, 65). «Nuestra ignorancia nos permitía vivir» $(115)^{6}$.

Siguiendo a Todorov quiero destacar los siguientes procedimientos de control de la memoria como los propios de totalitarismos como el nacionalsocialista: desaparición de las huellas, intimidación de la población, uso de eufemis-

[5] Levi, P.: Si esto es un hombre, Barcelona: Muchnik Editores, 2002; p. 10.

[6] Citado en Todorov, T.: Frente al límite, México: Ed. Siglo XXI, 2004; p. 153.

THÉMATA. Revista de Filosofía, No 51 enero-junio (2015) pp.: 53-69 doi: 10.12795/themata.2015.i51.03 
mos y la mentira o propaganda. Es por todos sabida la decisión hitleriana, tras la pérdida en Stalingrado, de convertir en cenizas todos los cuerpos que despreocupadamente habían sido apilados en fosas en los Lager alemanes. Este fue su modo de hacer desaparecer las huellas: convertir a seres humanos en cenizas. E incluso hicieron estallar las cámaras de gas y los crematorios en el otoño de 1944. También la intimidación de la población, ligada a la mentira y la propaganda fueron buenos aliados del nazismo, gracias a los cuales mantuvieron a la población en silencio, o como dirá Levi: los convirtió en sordomudos voluntarios. Como último procedimiento, los eufemismos fueron de lo más común en este totalitarismo: 'solución final' para referirse al exterminio judío, 'cuerpos' como modo de referirse a los seres humanos muertos, 'traslado' para referirse a deportación, 'tratamiento especial' hacía referencia a la muerte con gas, y un largo etc.

Considero que esta voluntad de escribir y narrar lo vivido muestra el primer elemento del pensamiento humanista definido por Todorov: la autonomía del yo del autor, que se compromete deliberadamente en esta tarea narrativa de reconstrucción e intento de comprensión de lo ocurrido. Porque este último punto, no lo olvidemos, será uno de los esenciales en su motivación: intentar comprender y dar un sentido a lo vivido. Esto es algo constitutivo de la especie humana, pero ante una situación semejante a la acaecida en el siglo XX se plantea una cuestión problemática, ya que podríamos correr el riesgo de trivializar el mal al intentar comprenderlo. Por eso dirá Primo Levi: «Tal vez lo que ocurrió no deba ser comprendido, en la medida en que comprender es casi justificar». Aun así, él estará hasta el final de sus días escribiendo, leyendo, recopilando información e intercambiando correspondencia con personas gracias a las cuales esperaba poder comprender, entender y dar sentido a lo ocurrido. Probablemente, moriría sin haberlo conseguido.

Tal y como podemos leer en la obra de E. Traverso titulada La historia desgarrada,

«Este racionalismo humanista era la fuente de una necesidad de comprensión y claridad, a la vez subjetiva y universal, en la que basaban su obra de testigos. El testimonio no solo responde a una necesidad interior de los supervivientes, sino también a una exigencia ética de la sociedad. Para Levi, la imposibilidad de comprender estimula aún más la necesidad de conocimiento» ${ }^{7}$.

Así pues, Primo Levi reivindicará un valor ético y pedagógico del testimonio que será el que le impulsará a seguir escribiendo hasta el final de sus días. La memoria de la ofensa será una condición esencial para restablecer la justicia, algo que Levi considera que no le corresponde a él, sino a los especialistas en jurisdicción.

Mientras que el recuerdo de Auschwitz pertenece a los supervivientes y morirá con ellos, la memoria de lo ocurrido debe generalizarse al conjunto

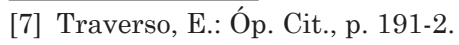

THÉMATA. Revista de Filosofía, Nº51 enero-junio (2015) pp.: 53-69 doi: 10.12795/themata.2015.i51.03 
de la sociedad. Solo de este modo podrá salvarse del olvido a los vencidos en la historia. Primo Levi lo reivindicó a lo largo de su obra: recordar es un deber para los supervivientes, del mismo modo que el escuchar debería serlo para todos los demás. Para él será importante que el mundo comprenda que tales experiencias tenían un sentido, y que los Lager no fueron un accidente, un mero imprevisto de la historia.

Para los estudiosos de Levi y de los relatos de los supervivientes en general, será importante en este punto la dialéctica que se establece entre la necesidad y la imposibilidad del testimonio (en términos de Shoshana Felman). Como dice E. Traverso:

«La rememoración es necesaria y se acerca a la verdad en la medida en que revela sus límites y reconoce la imposibilidad de narrar un proceso de destrucción que, por voluntad de sus autores, debía ser un acontecimiento sin sujeto, un crimen anónimo [...]. Las víctimas estaban obligadas a actuar como una pieza del engranaje que las destruía, en un proceso que borraba la huella del crimen al tiempo que lo perpetraba. El crimen pretendía ser anónimo, sin sujeto, y radical, sin testigos».

Como leemos en la obra de Levi, los Muselmänner son aquellos que realmente son los testigos integrales, los que sintieron la experiencia radical de las cámaras de gas, mientras que él, un salvado, solo puede dar testimonio en tanto que consiguió no vivir tal experiencia. Pero ellos ya están muertos, e incluso antes de morir no podrían haber dado cuenta de su situación, porque antes de la muerte del cuerpo, en los Lager se producía una muerte del alma, fruto de la animalización que forzaban los alemanes. Por eso Levi, el superviviente que no ha renunciado al lenguaje, que sigue recordando poemas que le devuelven un mínimo de humanidad (como veremos más adelante) se siente en la necesidad de dar testimonio, de hacer lo que todos estos testigos ya no pueden hacer, y por eso les hará partícipes de sus obras mediante el recurso retórico de la prosopopeya.

Sigo en este punto el análisis que ha hecho F. Rastier en su libro Ulises en Auschwitz de la obra de P. Levi, en la que afirma que «los poemas han sido escritos por un testigo hundido, mientras que las prosas son obras de un salvado» ${ }^{9}$. La prosa será el lenguaje del testigo, que facilita el regreso a la vida, mientras que la poesía, lenguaje del sobreviviente, anticipará la muerte de su narrador o bien tomará la palabra en lugar de los ya muertos. Así, mientras que la prosa del testimonio presenta una imposibilidad de dar la palabra a los difuntos, la prosopopeya lo hace posible mediante la ficción poética. Gracias a la escritura poética puede devolver al muerto la palabra. Los poemas de Levi no van dirigidos solo a los sobrevivientes, a quienes nadie comprende, sino que evocan también las voces de los hundidos. También dejará que los asesinos

[8] Traverso, E.: Óp. Cit., p. 195.

[9] Rastier, F.: Ulises en Auschwitz. Primo Levi el sobreviviente, Barcelona: Ed. Reverso, 2005; p. 62.

THÉMATA. Revista de Filosofía, No 51 enero-junio (2015) pp.: 53-69

doi: 10.12795/themata.2015.151.03 
tomen la palabra en sus poemas, pero estos se delatan justificándose, y continúan con vida. Así pues,

«No cabe duda de que el sobreviviente testimonia a favor de los muertos y contra los vivos, por las víctimas y contra los verdugos. Estos nos acusan, sin embargo, y hacen extensiva a los inocentes una culpabilidad que no asumen al atentar contra nuestra común humanidad. Negar su humanidad sería concederles el triunfo, puesto que ellos se la negaban a sus víctimas. No son monstruos, y la vergüenza que siente Levi es precisamente la de saber que son tan hombres como nosotros» ${ }^{10}$.

Mediante el recurso de la prosopopeya Levi reafirma el valor ético que supone devolverle la palabra al difunto: así permite que el sobreviviente restituya la voz de los hundidos, que les fue arrancada por la muerte. El testimonio del sobreviviente tiene en cuenta, entonces, el que podrían haber dado los hundidos, y trata de mostrar, en la medida de lo posible, cuál fue su experiencia. Como dice Rastier, la dualidad de prosa y poesía, que Levi calificó como su mitad racional y la otra mitad, muestra el 'desdoblamiento superpuesto del testimonio'. Así, mediante el recurso poético y la función crítica que tiene aparejada, nuestro autor conseguiría resolver la supuesta paradoja que se seguía de su condición de sobreviviente: la poesía logra reunir al sobreviviente y al testigo.

De manera íntimamente relacionada con su necesidad de narrar aquello que entiende como una ruptura crucial en su vida y también en la historia de la humanidad, y de comprender las motivaciones y el carácter de los seres humanos, encontramos en sus textos alusiones directas al lector, que tratan de implicarlo en lo que está leyendo y situarlo en la posición en que se encuentran los personajes de la novela. Un claro ejemplo de esto es el poema que precede a su primer libro -Si esto es un hombre-: se refiere directamente a los que vivimos en nuestras casas calientes y tranquilas, empujándonos a reflexionar sobre lo que de hecho ha ocurrido. Nos pide retener sus palabras y repetirlas a nuestros hijos para que aprendan de lo ocurrido, e incluso termina el poema con una sorprendente amenaza para aquel que no cumpla con el legado que transmite: «O que vuestra casa se derrumbe, / La enfermedad os imposibilite, / Vuestros descendientes os vuelvan el rostro».

A lo largo de toda su obra, Primo Levi tomará como receptor de su narración a un lector al que pide comprensión y sobretodo transmisión, esto es, que luche contra aquello que tanto miedo daba a los Häftlinge en los Lager y a los sobrevivientes después: el olvido y el silencio. Así, Levi considera su tarea principal el dar testimonio de lo ocurrido y no permitir que el olvido se apodere de esta parte tan desgraciada de la historia. Este será su modo de luchar contra el nazismo concretamente y contra todos los sistemas totalitarios en general, que intentan sustituir la verdad con la propaganda. De este modo, defiende la autonomía del yo pero también la finalidad del tú, que fue esencial

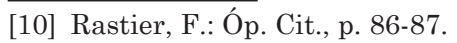

THÉMATA. Revista de Filosofía, Nº51 enero-junio (2015) pp.: 53-69 doi: 10.12795/themata.2015.i51.03 
para su supervivencia dentro del campo. Todos estos elementos los resume al final de su Apéndice de 1976 a Si esto es un hombre:

«El hecho de haber sobrevivido y de haber vuelto indemne se debe en mi opinión a que tuve suerte. [...] Quizás también me haya ayudado mi interés, que nunca flaqueó, por el ánimo humano y la voluntad no solo de sobrevivir (común a todos), sino de sobrevivir con el fin preciso de relatar las cosas a las que habíamos asistido y que habíamos soportado. Y finalmente quizás haya desempeñado un papel también la voluntad, que conservé tenazmente, de reconocer siempre, aun en los días más negros, tanto en mis camaradas como en mí mismo, a hombres y no a cosas, sustrayéndome de esa manera a aquella total humillación y desmoralización que condujo a muchos al naufragio espiritual» ${ }^{11}$.

\section{La finalidad del tú}

En lo que se refiere a este segundo elemento del humanismo, que se tiende a relacionar con la amistad, será uno de los temas más importantes de $\mathrm{Si}$ esto es un hombre. Para el autor, las relaciones amistosas con los demás hombres fueron aquello que le permitió seguir sintiéndose como un hombre y no como una mera bestia, y por ello, uno de los elementos esenciales de su supervivencia en el Lager. Esto lo ejemplifica con la relación que establece con un obrero civil italiano que le llevó un trozo de pan y las sobras de su comida durante seis meses, a cambio de nada, simplemente porque consideraba que se tenía que hacer el bien, sin esperar compensación ninguna. Y dice Primo Levi sobre él:

«Diré que creo que es a Lorenzo a quien debo estar vivo hoy; y no tanto por su ayuda material como por haberme recordado constantemente con su presencia, con su manera tan llana y fácil de ser bueno, que todavía había un mundo justo fuera del nuestro, algo y alguien todavía puro y entero, no corrompido ni salvaje, ajeno al odio y al miedo; algo difícilmente definible, una remota posibilidad de bondad, debido a la cual merecía la pena salvarse.

[...] Lorenzo era un hombre; su humanidad era pura e incontaminada, se encontraba fuera de este mundo de negación. Gracias a Lorenzo no me olvidé yo mismo de que era un hombre» ${ }^{12}$.

Y como él dirá en este mismo texto, fue la amistad que se estableció entre los enfermos dentro del Ka-Be (Krankenbau), durante los últimos días dentro del campo, aunque ya liberados de los alemanes por los bombardeos rusos, lo que les permitió organizarse y hacer de esos días algo ya humano. Esto es importante, porque serán los únicos que están marcados por una fecha concreta, en oposición a la vaguedad temporal que rodea todos los otros capítulos del libro. Este tendrá una estructura similar a la de un diario, en el que

[11] Levi, P.: Óp. Cit., p. 346-347.

[12] Ibídem, p. 209-210.

THÉMATA. Revista de Filosofía, №51 enero-junio (2015) pp.: 53-69 doi: 10.12795/themata.2015.i51.03 
se explicita qué ocurrió exactamente durante los diez últimos días que pasaron allí y cómo organizaron entre tres amigos la comida, limpieza y cura de todos los que estaban en el mismo barracón.

¿Por qué este cambio de incerteza temporal a citar exactamente qué días fueron? Considero que se debe al cambio radical en las relaciones interpersonales que se establecieron entre los Häftlinge. Durante el año entero que pasa en el campo, su relación con la mayoría de los compañeros e incluso con él mismo es siempre explicitada en términos zoológicos: 'gusanos', 'caballos de tiro', 'perros', 'bestias' e incluso utiliza el verbo alemán fressen para referirse a su modo de comer, verbo que hace referencia en buen alemán a la manera de comer de los animales. Mientras que en estos últimos diez días, ya se relacionan entre ellos como seres humanos propiamente, que se ayudan entre ellos y Los enfermos llegan incluso a ofrecer su trozo de pan a aquellos que trabajan para mantenerles con vida, cosa que antes era impensable en el Lager. Había algo que les unía, existía una amistad entre ellos, y gracias a ella recuperaron poco a poco su humanidad. En sus palabras:

«Parte de nuestra existencia reside en las almas de quien se nos aproxima: he aquí por qué es no humana la experiencia de quien ha vivido días en que el hombre ha sido una cosa para el hombre. Nosotros tres fuimos en gran parte inmunes, y nos debemos por ello mutua gratitud; es por lo que mi amistad con Charles resistirá el tiempo» ${ }^{13}$.

\section{La universalidad de los ellos}

Así pues, el ser humano es autónomo y tiene una voluntad y una libertad que le permiten escoger en sus acciones, y además es el ser humano mismo el fin último de sus actos. Ahora bien, ¿dónde podemos ver la universalidad de los ellos en la obra de Primo Levi? ¿Cómo se establece un espacio propio de los seres humanos? En este punto tal vez lo más destacable de nuestro autor es la consideración de que existe una 'esencia humana' de la que participan tanto las víctimas como los verdugos de los Lager. En contra de quienes quieren creer que los nazis son unos monstruos o unos enfermos, esto es, una desviación de lo que es un ser humano 'normal', Levi afirma:

«Hay que recordar que estos fieles, y entre ellos también los diligentes ejecutores de órdenes inhumanas, no eran esbirros natos, no eran (salvo pocas excepciones) monstruos: eran gente cualquiera. Los monstruos existen pero son demasiado pocos para ser realmente peligrosos; más peligrosos son los hombres comunes, los funcionarios listos a creer y obedecer sin discutir» ${ }^{14}$.

Esta matización es realmente importante, porque si para las víctimas era esencial poder afirmar que también eran seres humanos, Levi insistirá en

\footnotetext{
[13] Ibídem, p. 295.
}

[14] Ibídem, p. 342.

THÉMATA. Revista de Filosofía, Nº51 enero-junio (2015) pp.: 53-69 doi: 10.12795/themata.2015.i51.03 
el hecho de que esta humanidad era común entre víctimas y verdugos. Y tiene la necesidad de hacer hincapié en ello porque sus contemporáneos sí reconocen y reivindican la humanidad de las víctimas, pero la de los 'agentes del mal' parece problemática. Por ello dirá en 1986, en Los hundidos y los salvados:

«Estaban hechos de nuestra misma pasta, eran seres humanos medios, medianamente inteligentes, medianamente malvados: salvo excepciones, no eran monstruos, tenían nuestro mismo rostro, pero habían sido mal educados. Eran, en su mayoría, gente gregaria y funcionarios vulgares y diligentes» ${ }^{15}$.

Ahora bien, esto no puede llevar a la confusión de ambos: que los verdugos sean humanos no permite deducir que 'todos nosotros somos víctimas o asesinos y aceptamos estos papeles voluntariamente', tal como afirma Liliana Cavani sobre el sentido de su polémica película Portero de noche, contra la cual escribirá P. Levi en el mismo texto que acabamos de citar. Afirmaciones como esta tratan de eliminar la culpabilidad de unos y el sufrimiento de otros, de enmarañar la frontera entre ambos, y para Levi esto es sumamente perverso. Para un defensor del humanismo como él, que entiende al ser humano como un agente libre y por tanto, sujeto responsable de sus actos, no es aceptable una asimilación de este modo, que finalmente renuncia a todo posible juicio. Acusa a esta cineasta de coquetería estética, enfermedad moral o de ser cómplice ya que pretende confundir aquello que es inconfundible. Mientras que el sufrimiento de la víctima es injusto porque es inocente respecto del daño, el asesino puede sufrir, pero no es inocente. Por lo que no es tolerable su asimilación.

\section{El reconocimiento del horror}

Pasamos ahora a ver la primera de las dos características propias del humanismo crítico definido por T. Todorov, que parece directamente extraída de las páginas del último de los escritos de Primo Levi, puesto que el reconocimiento del horror del que son capaces los seres humanos es explícito en este texto en el sentimiento de vergüenza que embarga a los justos:

«Los justos de entre nosotros, ni más ni menos numerosos que en cualquier otro grupo humano, han experimentado remordimiento, vergüenza, dolor en resumen, por culpas que otros y no ellos habían cometido, y en las cuales se han sentido arrastrados, porque sentían que cuanto había sucedido a su alrededor en su presencia, y en ellos mismos, era irrevocable. No podría ser lavado jamás; había demostrado que el hombre, el género humano, es decir, nosotros, éramos potencialmente capaces de causar una mole infinita de dolor; y que el dolor es la única fuerza que se crea de la nada, sin gasto y sin trabajo. Es suficiente no mirar, no escuchar, no hacer nada» ${ }^{16}$.

[15] Levi, P.: Los hundidos y los salvados, Barcelona: El Aleph Editores, 2008; p. 189.

[16] Ibídem, p. 80.

THÉMATA. Revista de Filosofía, No51 enero-junio (2015) pp.: 53-69

doi: 10.12795/themata.2015.i51.03 
Estos tres últimos elementos serán los que utilizará Levi para definir cuál considera que es la 'culpa alemana' verdaderamente: no es que el pueblo alemán en su conjunto sea culpable directamente de lo que ocurría en los campos de concentración, cómplices de cada asesinato, pero sí son culpables de no querer ver, no querer escuchar y no querer hacer nada. Si no sabían de la existencia de estos campos es porque se habían transformado en sordomudos voluntarios. El gran responsable de tal catástrofe fue la indiferencia y la pasividad de la población alemana. Solo unos pocos tuvieron el valor de ayudar a sus amigos o compañeros, a pesar de que fueran judíos y por ello se estuvieran poniendo ellos mismos en peligro.

Considero este el lugar oportuno para tratar por qué Levi adopta deliberadamente un lenguaje sereno y sobrio de testimonio, y no muestra odio ni deseo de venganza hacia los alemanes. La actitud que él toma con respecto a los 'agentes del mal' será la siguiente: ni perdón ni venganza, sino justicia. Rechaza la venganza porque solo añade una nueva violencia a la precedente, que va ampliándose de manera pendular con el tiempo. Por otra parte, no odia a los alemanes porque considera el odio como algo personal, y en el Lager ya se encargaban de que no pudiese existir este contacto directo y personal entre los agentes del mal y sus víctimas. Prudentemente elegían una gran masa de intermediarios entre los guardianes y los detenidos, que será lo que Levi llama 'zona gris'. Tales individuos eran los que se encargaban del trabajo sucio, y normalmente eran reclutados entre los criminales de derecho común, esto es, alemanes que habían sido condenados y encarcelados.

Esta 'zona gris' que los nazis institucionalizaron será aquella en que la razón renuncia a explicar: 'Hier ist es kein Warum', y el corazón se niega a juzgar. Como dirá en el capítulo dedicado a La zona gris, en la última de sus obras, este era uno de los elementos menos comprensibles de los Lager: todos tendemos a simplificar el mundo que nos rodea, a identificar un 'nosotros' y un 'ellos', para saber de quién podemos fiarnos y de quién no. Pero esto era justamente lo contrario que encontraba en el Lager el recién condenado:

«Se ingresaba creyendo, por lo menos, en la solidaridad de los compañeros en desventura, pero estos, a quienes se consideraba aliados, salvo en casos excepcionales, no eran solidarios: se encontraba uno con incontables mónadas selladas, y entre ellas una lucha desesperada, oculta y continua. Esta revelación brusca, manifiesta desde las primeras horas de prisión - muchas veces de forma inmediata por la agresión concéntrica de quienes se esperaba fuesen aliados futuros-, era tan dura que podía derribar de un solo golpe la capacidad de resistencia. Para muchos fue mortal, indirecta y hasta directamente: es difícil defenderse de un ataque para el cual no se está preparado» ${ }^{17}$.

Esta gran zona que los nazis inventaron y situaron entre ellos y los Häftlinge comunes supuso la gran distancia de la que habla Levi para dar

[17] Ibídem, p. 35.

THÉMATA. Revista de Filosofía, №51 enero-junio (2015) pp.: 53-69 doi: 10.12795/themata.2015.i51.03 
cuenta de por qué no siente odio hacia el pueblo alemán, afirmación que repetirá a lo largo de toda su vida. Como tuvo que aprender forzadamente, es insoportable que se juzgue a un hombre no por aquello que es sino por el grupo al que pertenece. Esta actitud le parece aborrecible, y como tampoco acepta como sentimiento por el que guiarse la venganza, sino la razón, no deseará hacer él con los alemanes lo que ellos hicieron con él. Ahora bien, esto no implica que los perdonase, ya que se considera sin derecho a hacerlo, sino que afirmará que la 'gran culpa alemana' será su indiferencia, su actitud de 'oídos sordos' respecto a lo que estaba ocurriendo a pocos kilómetros de su casa. Aun así, Levi dará gran valor a los casos de alemanes que lucharon contra la imposición del totalitarismo bajo el que vivían, arriesgándose para ayudar a alguno de los proscritos por su país.

No quiero pasar por alto el sentimiento de vergüenza al cual Levi dedicará un capítulo entero en Los hundidos y los salvados. Este, como se puede ir deduciendo de lo que hemos visto hasta ahora, es un texto más reflexivo, donde se piensa Auschwitz en su contexto histórico y la ruptura de civilización que marca en la historia de la humanidad. Al contrario de lo que ocurre en Si esto es un hombre, no solamente se basa en el recuerdo, sino que se ha enriquecido con la experiencia y el contacto con otros supervivientes y la perspectiva que suponen cuarenta años de reflexión. Esta obra está, entonces, a medio camino entre la historiografía y la memoria, y será su intento personal de reflexionar teóricamente sobre aquello que vivió y experimentó. Y uno de los puntos básicos sobre los que medita es el sentimiento de vergüenza que sienten los supervivientes a tres niveles ${ }^{18}$.

El primero de ellos será la vergüenza del recuerdo. Levi afirmará que la vergüenza de haber sido objeto de humillaciones y ofensas será indeleble, por muchas décadas que pasen; él sigue sintiendo vergüenza de los actos y situaciones por las que tuvo que pasar para poder sobrevivir obedeciendo unas órdenes que consideraba de lo más bajas. Uno de los recuerdos que le atormentará por siempre será su asistencia, narrada en Si esto es un hombre, a la ejecución 'del último', el último hombre justo entre todos ellos que tuvo el coraje de participar en la insurrección del Sonderkommando de Birkenau haciendo explotar uno de los crematorios. El condenado les dice que él es el último hombre, y Levi confirma que esto es cierto: porque todos los demás que asisten al ahorcamiento ya no son realmente hombres, sino seres domados, débiles, acabados, dignos de morir. Esto provocó un gran sentimiento de vergüenza entre todos los Häftlinge que incluso evitaban mirarse unos a otros a la cara.

Un segundo ingrediente, propio ya solamente de los que consiguieron escapar de los Lager, es la vergüenza de sobrevivir. A pesar de lo que podría parecer, el hecho de haber sobrevivido atormentó a muchos de los que lo con-

[18] Seguimos en esta clasificación lo expuesto por Todorov, T.: Frente al límite, Ed. Cit., p. 268-270.

THÉMATA. Revista de Filosofía, No 51 enero-junio (2015) pp.: 53-69

doi: 10.12795/themata.2015.i51.03 
siguieron como una culpa que les persiguió prácticamente hasta la muerte, y en algunos incluso la provocó, como en el caso del suicidio de Jean Améry (y quizás el de P. Levi). El sobreviviente siente que vive en el lugar de otro, de un compañero muerto. Y dirá que solo sobrevivieron los peores, aquellos que consiguieron algún privilegio o trato de favor, los que se agarraron a la vida ferozmente; y eso les hace sentirse peor, sentirse parte de ellos. Sentirán el estar vivos como una falta que han hecho a los demás, como una injusticia: el sobreviviente no tiene de qué enorgullecerse:

\footnotetext{
«¿Es que te avergüenzas de estar vivo en el lugar de otro? Y sobre todo ¿de un hombre más generoso, más sensible, más sabio, más útil, más digno de vivir que tú? No puedes soslayarlo: te examinas, pasas revista a tus recuerdos [...] Se trata solo de una suposición, de la sombra de una sospecha: de que todos seamos el Caín de nuestros hermanos, de que todos nosotros (y esta vez digo 'nosotros' en un sentido muy amplio, incluso universal) hayamos suplantado a nuestro prójimo y estemos viviendo su vida. Es una suposición, pero remuerde; está profundamente anidada, como la carcoma; por fuera no se ve, pero roe y taladra ${ }^{19}$.
}

Por último, la tercera forma de vergüenza será la más abstracta pero quizá la más universal, con la que nos podemos sentir más identificados: la vergüenza de ser humano. Esta procede de la común humanidad entre verdugos y víctimas: todos estamos hechos 'de la misma pasta' y esto es lo que nos puede hacer sentir culpables de ser hombres, ya que estos han sido capaces de crímenes tan atroces como los de Auschwitz y Kolyma.

Será importante para nuestro autor intentar comprender este agujero negro del siglo XX sin hacer ningún tipo de concesión a la teología ni a las concepciones deterministas de la historia (como sí hicieron algunos de los Häftlinge con los que compartió meses de sufrimiento y de los cuales afirma que aguantaron mejor las vejaciones, quizá porque consideraban que tenían algún significado). Tal como explicita E. Traverso, para Levi Auschwitz fue «una experiencia profunda y eminentemente humana, en el sentido de mostrar, como nunca antes, todo el mal del que el hombre es capaz (de infligir y de padecer) $»^{20}$.

Tal vez en este punto de no dar concesión ninguna a la teología sea esencial comentar la relación de P. Levi y el judaísmo, que pese a estar íntimamente relacionado con la autonomía del yo, he preferido situarlo en este contexto porque no debemos olvidar que al fin y al cabo lo trasladaron al Lager por su condición de judío. Según su propio testimonio, era un judío profundamente asimilado en Italia, y afirma que se volvió judío en Auschwitz. Fue allí donde escuchó por primera vez palabras yiddish y descubrió el judaísmo en sus formas nacionales. A pesar de las leyes raciales, él se consideraba italiano, y el mundo de lo que llamó Ostjudentum le resultaba extraño, y de esto dará

[19] Levi, P.: Los hundidos y los salvados, Ed. Cit., p. 76.

[20] Traverso, E., Óp. Cit., p. 186.

THÉMATA. Revista de Filosofía, Nº51 enero-junio (2015) pp.: 53-69

doi: 10.12795/themata.2015.i51.03 
cuenta en su obra Se non ora quando? Para estos judíos, Levi aparecía como una cierta anomalía, pues como le dice tajantemente una chica joven que encuentra en el viaje en tren desde el Lager a su ciudad natal, narrado en La tregua: «iNo habláis yiddish: luego no sois judíos!» ${ }^{21}$. Para ella, esto resultaba más que evidente. Pero Levi fue criado en un medio bastante laico, arraigado en la cultura italiana, ajeno a la tradición hebraica y ateo por convicción filosófica y finalmente también por la experiencia vivida en los campos de concentración, ya que según él: Dios no puede existir en un mundo que ha engendrado Auschwitz.

\section{Afirmación de la posibilidad del bien}

La última de las características del humanismo crítico, que finalmente es el único posible después de lo que supuso Auschwitz, es la afirmación de la posibilidad de realizar el bien a individuos concretos e individuales, tomándolos como fin último de sus acciones. En este punto trataré las relaciones que se establecieron entre los Häftlinge dentro del campo y que reafirmaron su humanidad. Esto está directamente relacionado con lo que he comentado en el segundo apartado (finalidad del tú) sobre Lorenzo y la importancia que tuvo su relación para la supervivencia no solo física, sino también moral, de P. Levi. Los casos en que actúa la conciencia moral en estas situaciones extremas confirman, finalmente, La posibilidad de elección, aunque dentro de ciertos límites, y por tanto, la existencia de vida y acción moral incluso en las peores situaciones que podamos imaginar.

Otra de las lecciones que Levi afirma que le salvaron la vida le fue dada por el sargento Steinlauf a comienzos de su detención: mantenerse limpio para seguir sintiéndose humano a sus propios ojos. Limpiarse cada día, cuando las condiciones empujan hacia la actitud contraria, se sentirá como un síntoma de vitalidad necesario, como instrumento de supervivencia moral. Será una de las acciones que les mantendrá dentro de la humanidad e incluso la experiencia de los testimonios demostrará que mantenerse limpio inspira el respeto de los otros detenidos, y por tanto, las oportunidades de sobrevivir. Tal como dice en Si esto es un hombre, la lección de este sargento será crucial:

«Precisamente porque el Lager es una gran máquina para convertirnos en animales, nosotros no debemos convertirnos en animales; que aun en este sitio se puede sobrevivir, y por ello se debe querer sobrevivir, para contarlo, para dar testimonio; y que para vivir es importante esforzarse por salvar al menos el esqueleto, el armazón, la forma de la civilización. Que somos esclavos, sin ningún derecho, expuestos a cualquier ataque, abocados a una muerte segura, pero nos ha quedado una facultad y debemos defenderla con todo nuestro vigor porque es la última: la facultad de negar nuestro consentimiento. Debemos, por consiguiente, lavarnos la cara sin jabón, en el agua sucia, y secarnos con

[21] Levi, P.: La Tregua, Barcelona: El Aleph Editores, 2005, p. 182.

THÉMATA. Revista de Filosofía, No 51 enero-junio (2015) pp.: 53-69

doi: 10.12795/themata.2015.i51.03 
la chaqueta. Debemos dar betún a los zapatos no porque lo diga el reglamento sino por dignidad y por limpieza. Debemos andar derechos, sin arrastrar los zuecos, no ya en acatamiento de la disciplina prusiana sino para seguir vivos, para no empezar a morir» ${ }^{22}$.

La segunda de las virtudes cotidianas que afirman la posibilidad del bien del ser humano incluso en las peores condiciones será la del cuidado, actitud maternal por excelencia, por lo que estará mejor documentado en los Lager en que había mujeres. El cuidado contiene en sí mismo su propia recompensa, puesto que hace feliz a quien lo practica. Como podemos leer en Todorov, para una mujer el cuidado del otro era la única manera de mantenerse como un ser humano digno en un Lager. Era visto como un acto de autoconservación, más que como un acto heroico. Esta segunda virtud la vemos en la obra de Levi cuando ayuda a sus compañeros enfermos en el $\mathrm{Ka}$-Be, como ya he señalado anteriormente, aunque sería algo más patente en otros campos.

Añade a la dignidad y al cuidado una tercera virtud cotidiana: la actividad del espíritu. En este punto, destaca el capítulo dedicado a El canto de Ulises en Si esto es un hombre, partiendo del cual François Rastier escribió su libro sobre la importancia de la poesía dentro de la obra de P. Levi, el ya citado Ulises en Auschwitz. Primo Levi el sobreviviente. En este capítulo, Levi recita fragmentos de la Divina comedia en italiano a su compañero Jean le Pikolo a cambio de sus lecciones de francés. Esta pequeña actividad intelectual fue capaz de crear un islote de libertad y elevación espiritual en medio de la miseria en que vivían. En Los hundidos y los salvados recuerda esta caminata por la montaña con Jean acompañada del intento de recordar cómo continuaba el poema de Dante.

«Habría dado verdaderamente el pan y el potaje, es decir, la sangre, por salvar de la nada aquellos recuerdos que hoy, con el soporte seguro del papel impreso, puedo refrescar cuando quiera, y gratis, y que por eso parecen valer poco. Entonces y allí, valían mucho. Me permitían volver a atar un nudo con el pasado, salvándolo del olvido y reforzando mi identidad. Me convencían de que mi mente, aunque acosada por las necesidades cotidianas, no había dejado de funcionar. Me valoraban, a mis ojos y a los de mi interlocutor. Me proporcionaban una tregua efímera pero no necia, también liberadora y diferencial: un modo, en fin, de encontrarme a mí mismo» ${ }^{23}$.

$\mathrm{Al}$ contrario de lo que pensadores como Améry han vivido respecto de sus recuerdos intelectuales en los campos de concentración, para Levi fue realmente esencial, una virtud cotidiana que logró reconciliarlo con su humanidad, recordarle que pese a todo continuaba siendo humano, seguía pudiendo admirar la belleza de las cosas gracias al recuerdo del arte y la poesía. Además, destaca en esta experiencia la importancia de aprender la lengua de los compañeros, especialmente de aquellos que conocían la lengua en la que hablaban

[22] Levi, P.: Si esto es un hombre, Ed. Cit., p. 64-65.

[23] Levi, P.: Los hundidos y los salvados, Ed. Cit., p. 130.

THÉMATA. Revista de Filosofía, Nº51 enero-junio (2015) pp.: 53-69 doi: 10.12795/themata.2015.i51.03 
los Kapos. Uno de los capítulos de su último libro está dedicado a esto: a la importancia que tuvieron para él las clases de alemán que le dio un compañero a cambio de raciones de pan nada más entrar en el Lager, y las clases que él después dio a otros compañeros, imprescindibles para comprender las órdenes y no morir a causa de la incomprensión lingüística que reinaba en esa gran 'torre de Babel'.

Como dirá Todorov en Frente al límite, estas tres virtudes cotidianas que permiten devolver la humanidad a los seres humanos y reafirman la posibilidad del bien, dan cuenta de los tres primeros elementos que he usado para caracterizar al humanismo. En la dignidad, el yo se dirige a sí mismo; en el cuidado de los demás, se dirige a uno o varios tú, esto es, a seres humanos con los cuales establece una relación de reciprocidad; y en la actividad del espíritu se dirige a unos ellos, que permanecen anónimos.

\section{Conclusión}

Como conclusión, quiero defender que la humanidad sí continúa el legado de Primo Levi, puesto que los alemanes 'no se salieron con la suya'. Tal como dice Todorov en Memoria del mal, tentación del bien:

«El intento de los nazis de disimular sus fechorías en los campos de concentración y exterminio se saldó con un completo fracaso: pocos acontecimientos de la historia contemporánea, ya lo he dicho, están tan bien documentados. Los supervivientes de estos campos se sintieron a menudo investidos de una misión - dar testimonio - y no dejaron de hacerlo, algunos a la misma liberación; otros, cuarenta o cincuenta años más tarde» ${ }^{24}$.

Aun así, Levi no está del todo convencido de que sus contemporáneos hayan comprendido realmente qué significan Auschwitz y Kolyma; no parecen haber entendido el peligro del que nos advierten. Teme el italiano que los mismos males adopten en la actualidad otras caras y que no sepamos reconocerlos, esto es, teme que vuelva a darse una situación como aquella y que no podamos reaccionar a tiempo. Observar los crímenes del régimen comunista de Pol Pot y el genocidio ruandés le incita a pensar que finalmente no hemos comprendido nada.

Levi afirmará que la esencia de lo que tiene que decir es lo siguiente: «sucedió, por tanto, puede volver a suceder». Su intención, pues, será ponernos en alerta a todos sus lectores y a toda la humanidad en general respecto a este tipo de situaciones, que en tanto que se han dado en un momento histórico, pueden volverse a dar, aunque con otro rostro y por eso nos puedan parecer distintas en su fase inicial. Su escritura será un aviso y una crítica ante aquellos que consideran que el ser humano necesita del conflicto, de la guerra, y que una paz muy duradera sería algo anómalo históricamente. Se opone también a

[24] Todorov, T., Memoria del mal, tentación del bien, Ed. Cit., p. 215.

THÉMATA. Revista de Filosofía, №51 enero-junio (2015) pp.: 53-69 doi: 10.12795/themata.2015.i51.03 
quienes defienden una violencia preventiva, ya que en contra de lo que algunos piensan, la violencia solo genera más violencia, que va creciendo en forma de espiral hasta que nada puede ya huir de ella. Como dirá en la conclusión de su último libro, escrito pocos meses antes de morir:

«Satanás no es necesario: no tenemos ninguna necesidad de guerras ni de violencias, en ningún caso. No hay problemas que no puedan resolverse alrededor de una mesa siempre que haya buena voluntad y confianza mutua: o también miedo mutuo» ${ }^{25}$.

Para terminar, no me gustaría pasar por alto una alternativa de comprensión del humanismo que propone F. Rastier en el libro que he comentado: Ulises en Auschwitz. En este afirma que Levi no tuvo la intención de teorizar la última forma de humanismo, quizá el único posible después de los Lager tanto alemanes como rusos y de la explosión de las bombas atómicas: el humanismo de la supervivencia, el de la humanidad del hombre. En este último humanismo,

«La protección de la naturaleza y la supervivencia de la población aparecen aquí fundidas en una misma causa. El humanismo del desafío y el de la sabiduría práctica dan paso hoy a un humanismo de la prevención y la conservación, cuya figura central ya no es el científico o el filósofo, sino la víctima» ${ }^{26}$.

Esta encarna en silencio a una humanidad víctima de la barbarie que su misma existencia denuncia. Esto da cuenta de que, tras el exterminio, el concepto de 'humanidad' no se impone como una evidencia, sino que es un concepto por (re)construir. Y propone al final de su texto diversas vías que pueden conducir a esta necesaria reconstrucción: 1) el ideal de educación de las humanidades, que reclama una renovación; 2) una antropología cultural que tome en cuenta la génesis y la historia comparada de las culturas y reformule el cosmopolitismo kantiano mediante el universalismo que lo impulsó; 3) una reflexión sobre las artes que combata el prejuicio de que ética y estética deben estar separadas, y que tome en cuenta que cada acto humano se lleva a cabo desde la responsabilidad; 4) una ética que se encuentra, a manera de praxis, en la literatura del exterminio, esto es, en el testimonio que permite al sobreviviente comprenderse y ejercer la justicia.

Se tratará, pues, de formular un programa político para el mundo de hoy que nace de una esperanza razonable, que se une directamente con la afirmación de Primo Levi de la no necesidad de la guerra entre los seres humanos: el fin de la guerra y el exilio, un mundo reconstruido gracias a la paz y la justicia entre todos los seres humanos ya que, al fin y al cabo, participamos todos de una misma naturaleza.

[25] Levi, P.:Los hundidos y los salvados, Ed. Cit., p. 187.

[26] Rastier, F., Óp. Cit., p. 183.

THÉMATA. Revista de Filosofía, Nº51 enero-junio (2015) pp.: 53-69 doi: 10.12795/themata.2015.i51.03 


\section{Referencias bibliográficas:}

Levi, P., Si esto es un hombre, Barcelona: Muchnik Editores, 2002.

Levi P., La Tregua, Barcelona: El Aleph Editores, 2005.

Levi, P., Los hundidos y los salvados, Barcelona: El Aleph Editores, 2008.

Rastier, F., Ulises en Auschwitz. Primo Levi el sobreviviente, Barcelona: Ed. Reverso, 2005.

Todorov, T., Frente al limite, Mexico: Ed. Siglo XXI, 2004.

Todorov, T., El jardín imperfecto. Luces y sombras del pensamiento humanista, Barcelona: Ed. Paidós, 2011.

Todorov, T., Memoria del mal, tentación del bien. Indagación sobre el siglo XX, Barcelona: Ed. Península, 2002.

Traverso, E., La historia desgarrada, Barcelona: Ed. Herder, 2001. 
